\title{
A multipurpose test rig for district heating substations: domestic hot water preparation and keep-warm function comparison
}

\author{
Jad Al Koussa ${ }^{1,3 *}$, Rutger Baeten ${ }^{1,3}$, Nico Robeyn ${ }^{2,3}$, and Robbe Salenbien ${ }^{1,3}$ \\ ${ }^{1}$ VITO NV, Energy Technology Unit, Thermal Energy Systems Group, Boeretang 200, BE-2400 Mol, Belgium \\ ${ }^{2}$ KU Leuven (University of Leuven), Celestijnenlaan 300 - Box 2421, B-3001 Leuven, Belgium \\ ${ }^{3}$ EnergyVille, Thor Park 8300, 3600 Genk, Belgium
}

\begin{abstract}
A well performing District Heating Substation (DHS) is crucial for the efficiency of the District Heating $(\mathrm{DH})$, especially with the shift towards low temperature $4^{\text {th }}$ generation $\mathrm{DH}$ systems. For this reason, testing and characterization of commercially available DHSs becomes important to estimate their effect on the $\mathrm{DH}$ network. Within the thermo-technical laboratory of EnergyVille, a multipurpose test rig has been built for testing DHSs. In this setup, different DH conditions and heat demand profiles for space heating and for Domestic Hot Water (DHW) can be emulated. Independent tests have been performed on $4 \mathrm{DHSs}$ from three different manufacturers, focused on the DHW preparation for low $\mathrm{DH}$ supply temperature and on the stand-by/keep-warm operation of the substations. The latter maintains a certain temperature within the heat exchanger to avoid delays in the delivery of DHW. The results showed that improvements are needed on DHW production for lower DH supply temperatures. Also, enhancements are needed to reduce losses from the keep-warm function. Given that $\mathrm{DH}$ systems can have thousands of substations, this will reduce the overall losses and improve the performance of the $\mathrm{DH}$ network.
\end{abstract}

\section{Introduction}

A District Heating Substation (DHS), also referred to as Heat Interface Unit (HIU), is the interface between the District Heating (DH) grid and the consumer, as depicted in Fig. 1. It provides the consumer (house or apartment or multi-storey building) with Space Heating (SH) either directly, via a direct connection between the SH pipes and the DH pipes, or indirectly via a heat exchanger, and it also delivers Domestic Hot Water (DHW) via a heat exchanger for sanitary purposes. The indirect space heating connection is the most commonly used type since it provides a hydraulic separation between the $\mathrm{DH}$ water and the space heating water, reducing risks and providing better overall control [1].

To control the substation, a central controller is usually available. This controller receives feedback from multiple sensors such as temperature sensors within the substation, temperature sensors installed in the space to be heated, and from temperature sensors placed outdoor. Combined with input commands from the user interface, the information is used to determine the heating setpoint and consequently the required space heating supply temperature. The DHW temperature can be controlled using the same controller or through a self-regulating valve.

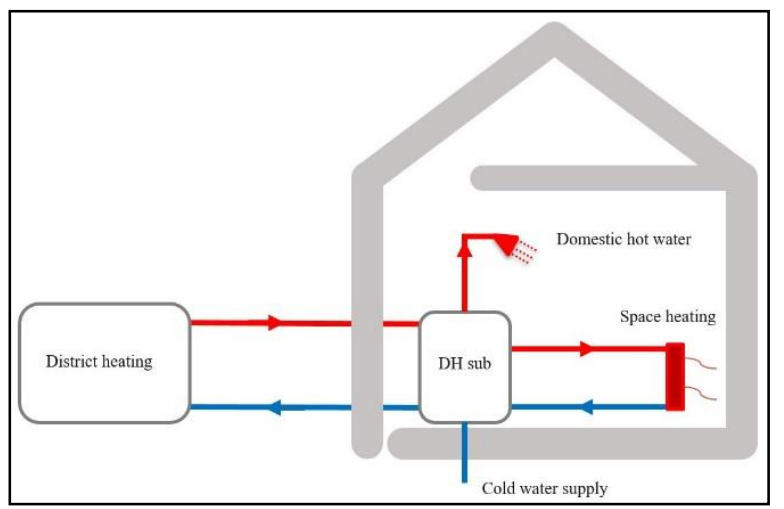

Fig. 1. District heating substation concept

With the shift towards lower supply temperatures in DH systems, the role of DHSs becomes of great importance because of their direct influence on the return temperature. This temperature should be kept as low as possible to help improving the efficiency of renewable energy sources as well as the technology mix that can be coupled to the network, to help increasing the potential of waste heat by for instance better heat recovery from flue gas condensation, or to help reducing the losses in the district and increasing the capacity [2]. Also, if this return temperature is not kept low, DH utilities cannot guarantee

\footnotetext{
* Corresponding author: jad.alkoussa@,vito.be
} 
a low supply temperature [3], leading to a decrease in the DH efficiency.

Despite the importance of the low return temperature, recent research has shown that around $74 \%$ of DHSs perform sub-optimally [4], i.e. having higher return temperature than expected. This sub-optimal performance becomes a bottleneck with lower supply temperatures. The faulty operation of DHSs is due to multiple factors, namely badly commissioned secondary heat supply systems and poor substation control $[3,4]$.

Sub-optimal secondary heating systems can be improved by hydraulically balancing the system to make sure that it is able to deliver the correct amount of heat to all heat delivery points. This is done by adjusting the balancing valves in the system so that the opening position of the valves increases with the distance from the substation's heat exchanger to ensure the same flow rate in the system, delivering heat to the more remote radiators [5]. If this is not done correctly, the return temperature from the installation will increase, increasing the return temperature to the DH network [5]. Also, the radiators in the space heating system are most commonly controlled by thermostatic radiator valves. If those valves are not working correctly, the flow in the radiator system will be uncontrollable [6].

Poor substations control can be improved by improving components and control strategies within the substations. To properly understand the behaviour of such control under operational conditions, characterisation of DHSs becomes vital. For this reason, a DHS test rig was developed, and a series of tests were performed on 4 substations from 3 different manufacturers. Those tests focused on the DHW preparation and the stand-by/ keep warm function: a built-in function that keeps the DHW heat exchanger at a certain temperature during stand-by to avoid DHW delivery delays and thereby ensuring the highest possible comfort for the end-user. More specifically, the tests focused on low DH supply temperature $\left(55^{\circ} \mathrm{C}\right)$ to examine the readiness and the capability of those substations to perform in low temperature DH systems. Few to none commercially available systems are built specifically for these lower temperature regimes, and many manufacturers claim adequate performance to be in effect even outside the design boundaries.

In the next sections, a description of the test rig is provided, followed by the test results and ending with conclusions.

\section{Test rig}

Within the thermo-technical laboratory at EnergyVille, a test rig was developed in which DH supply conditions, DHW demand and SH demand can be emulated. In Fig.2 the schematic indicating the different components of the rig can be seen and Fig.3 shows the physical implementation. This setup can be used to test, under different conditions, equipment and components that use a heat source to deliver space heating and/or DHW to a dwelling, such as water-to-water heat pumps or DHSs. As shown, temperature, volume flow and pressures are measured on the primary and the secondary sides of the equipment. In this work, the focus is on DHSs. On the DH side, two flowmeters are placed in parallel, one to measure relatively high $\mathrm{DH}$ flows during DHW or $\mathrm{SH}$ operation and the other one for the low/leak flows that occur when the DHS is on stand-by, i.e. no DHW and no SH demand. The use of two flow meters is needed because the high flowmeter cannot accurately detect and measure the low flows taking place during the stand-by case.

The primary side, or district heating supply side, is connected to the lab supply through a heat exchanger to control the required temperature set-point of the $\mathrm{DH}$ supply. Moreover, a flow control valve is placed on a bypass before the DHS to ensure the continuous operation of the DH circulation pump, reducing delays in reaching the DH supply temperature.

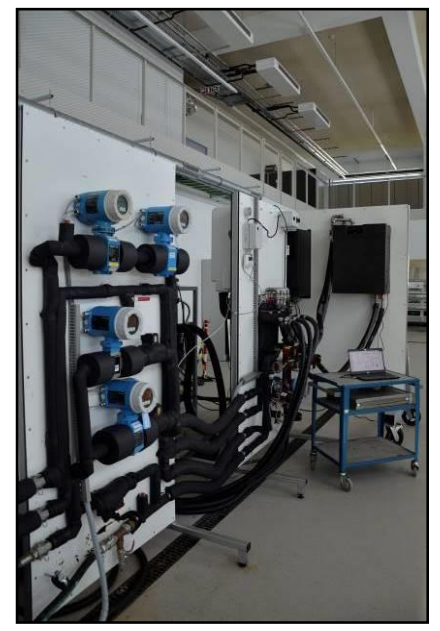

Fig.3. The test rig implemented in the laboratory.

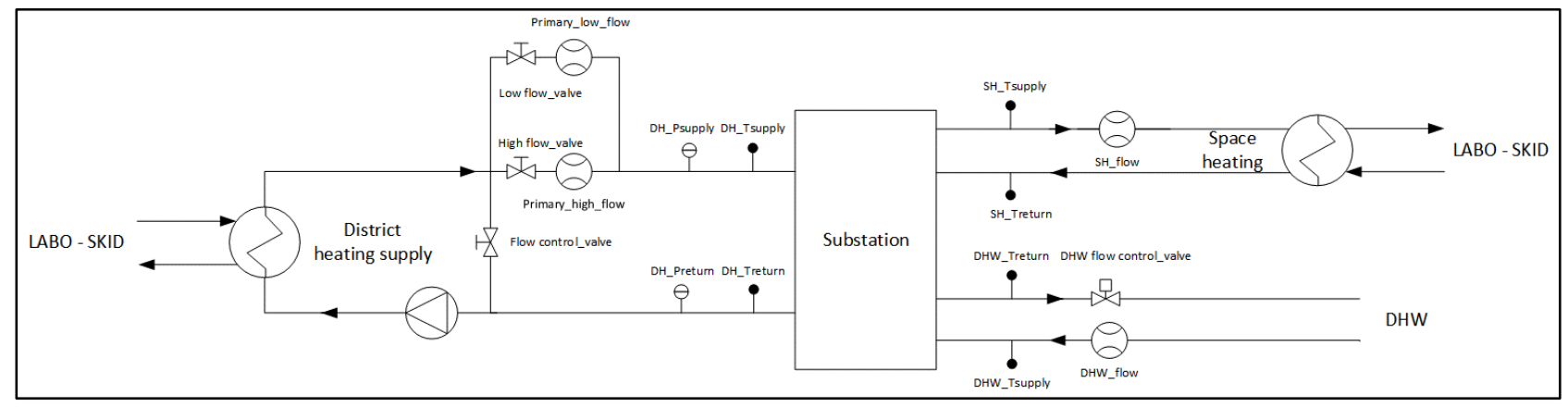

Fig.2. Schematic of the test rig. 
The SH demand is emulated by performing hardwarein-the-loop simulations and setting the return temperature to the DHS via a heat exchanger, representing the return temperature from a given heating system. This heat exchanger is also connected on the secondary side to the fixed laboratory's infrastructure. A controllable valve sets the DHW demand to the required flow using the flow meter installed on the cold water supply circuit. All the data communication from and to the different sensors is performed through a central Programmable Logic Controller (PLC).

\section{Tests performed}

Tests were performed on 4 DHSs from 3 different manufacturers, having the same power range, i.e. designed for apartments and single-family houses. The DHW and SH preparation methods of each of the DHSs are shown in Table 1.

Table 1. Properties of the tested substations, $\mathrm{SR}=$ selfregulating.

\begin{tabular}{|c|c|c|}
\hline DHS & $\begin{array}{c}\text { Space } \\
\text { Heating }\end{array}$ & DHW \\
\hline SubstA & Indirect & Electronic valve \\
\hline SubstB & Indirect & $\begin{array}{c}\text { SR thermostatic proportional valve } \\
\text { with differential pressure control }\end{array}$ \\
\hline SubstC & Indirect & SR thermostatic valve \\
\hline SubstD & Direct & SR thermostatic valve \\
\hline
\end{tabular}

For space heating, the control is usually the same: by comparing the actual room temperature to the room setpoint temperature defined by the user, the controller determines if there is a need for space heating, sending a switch on/off command to the SH circulation pump. Also, this controller determines the space heating supply temperature using the built-in heating curve. It is becoming more common to use the outdoor temperature as well to determine this heating supply temperature. Once this temperature is set, the controller reads in the SH supply temperature and controls the actuator of the space heating control valve accordingly. The outline of the substation's internal components can be seen in Fig.4. and Fig.5.

The DHW temperature regulation can be performed using two different approaches. The first one, shown in Fig.4. is based on electronic control. In this approach the user sets the DHW temperature parameter to the desired value during the setup of the substation. When a DHW demand occurs, the central controller of the substation reads the DHW supply temperature and controls the actuator of the control valve installed at the primary side of the DHW heat exchanger. By getting a continuous feedback from the temperature sensor, the central controller can maintain the required opening of the control valve and subsequently the DHW temperature.

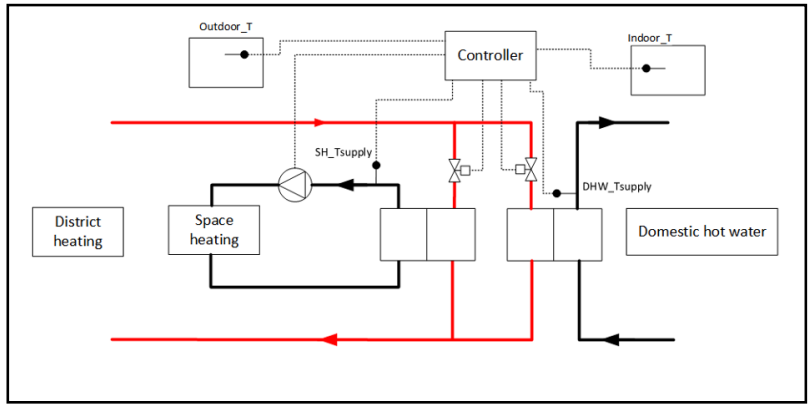

Fig. 4. The main components of a district heating substation with central control for space heating and for DHW.

The second approach is based on a self-regulating (SR) valve, as shown in Fig.5. The control of the DHW is completely independent of the central controller. A temperature sensor installed at the DHW supply circuit or within the heat exchanger and it is directly connected to a self-regulating valve. This valve is pre-set to provide the desired DHW temperature under given conditions of the district heating supply. The valve's position is also set during the setup of the substation by the installer, by manually setting the valve to a value corresponding to a desired DHW supply temperature.

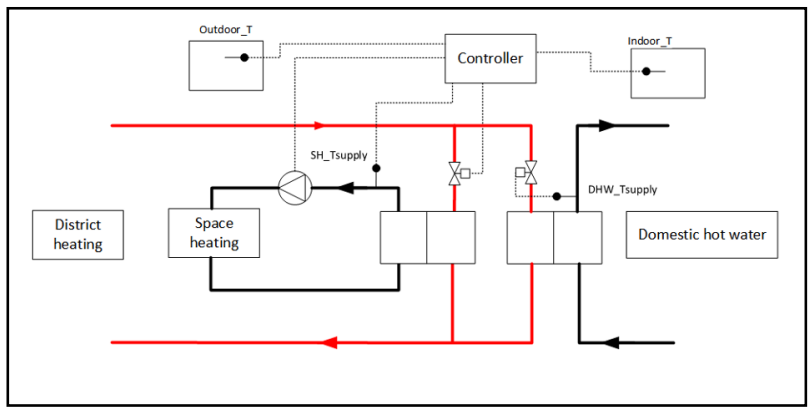

Fig.5. The main components of a district heating substation with central control for space heating and a self-regulating valve for DHW.

\subsection{DHW tests}

The goal of this series of tests is to examine how close to the set point can a substation in practice operate for different DHW flow rates, for a relatively low DH supply temperature.

During those tests, no SH demand occurred. The DH supply temperature was set to $55{ }^{\circ} \mathrm{C}$, and the $\mathrm{DHW}$ temperature to $45{ }^{\circ} \mathrm{C}$ for a DHW flow rate of $6 \mathrm{~L} / \mathrm{min}$, equivalent to what is usually needed for a normal bath (before mixing it with cold water). Then, the DHW flow was varied in steps of $1 \mathrm{~L} / \mathrm{min}$ every 20 minutes, from 5 to $12 \mathrm{~L} / \mathrm{min}$. For the substations with $\mathrm{SR}$ valves, the temperature was set by manually turning the knob on the valve and measuring the DHW temperature until a temperature of $45^{\circ} \mathrm{C}$ is reached (for a DHW flow rate if 6 $\mathrm{L} / \mathrm{min}$ ). For the electronically controlled valve, the setpoint was simply set using the interface to the 

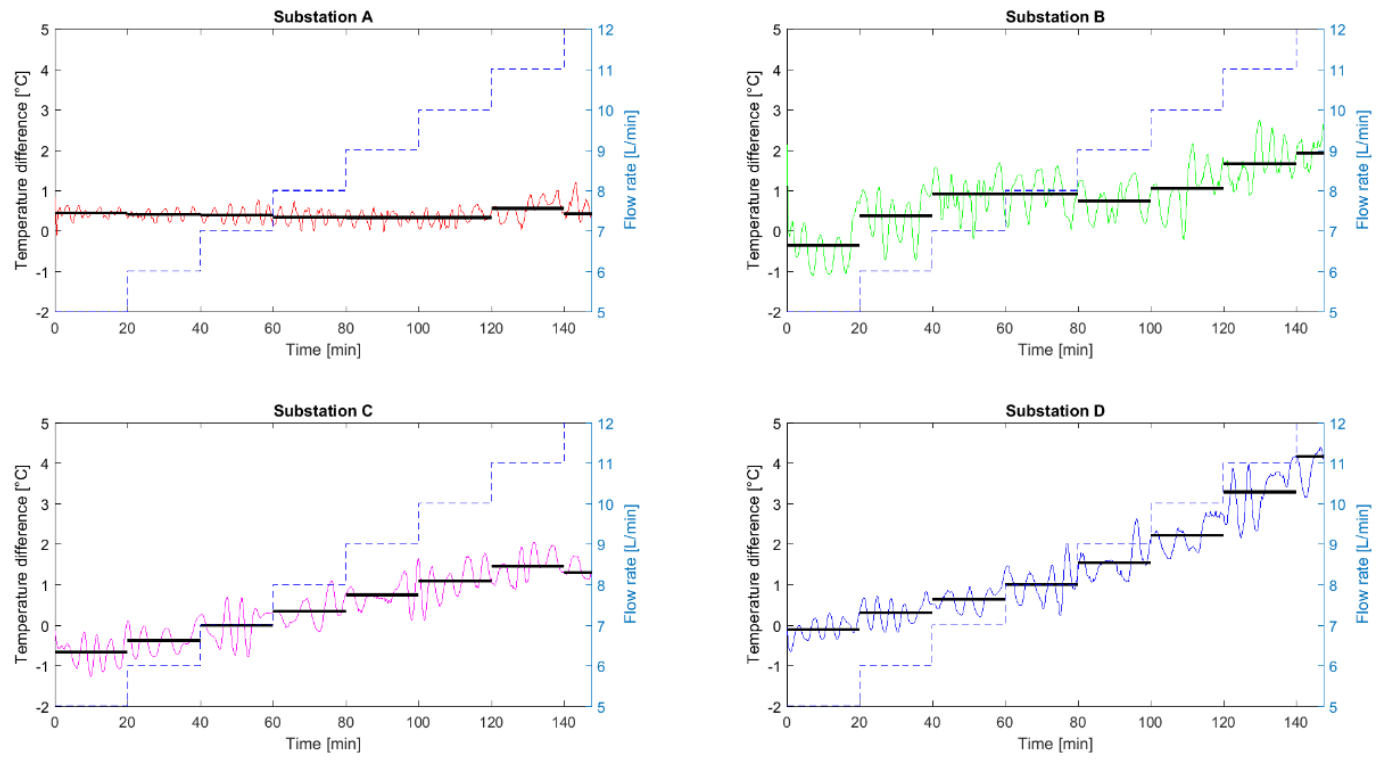

Fig.6. Deviation of the DHW temperature from the set point of $45^{\circ} \mathrm{C}\left(45-T_{-} D H W\right)$ for the 4 DHSs. A linear approximation is shown for each of the graphs.

substation's controller. Regarding the monitoring, data was collected with a time-step of 1 second.

Fig.6. shows the deviation of the DHW temperature from the set-point of $45{ }^{\circ} \mathrm{C}$, i.e. $45-T_{-} D H W{ }^{\circ} \mathrm{C}$, on the primary $y$-axis and the DHW flowrate on the secondary $y$-axis for the 4 substations. For each flow rate, the average temperature deviation is also plotted (black line). Moreover, Fig.7. shows the average deviation of the DHW temperature from the setpoint of $45{ }^{\circ} \mathrm{C}$ for the 4 substations as a function of the DHW flow rate.

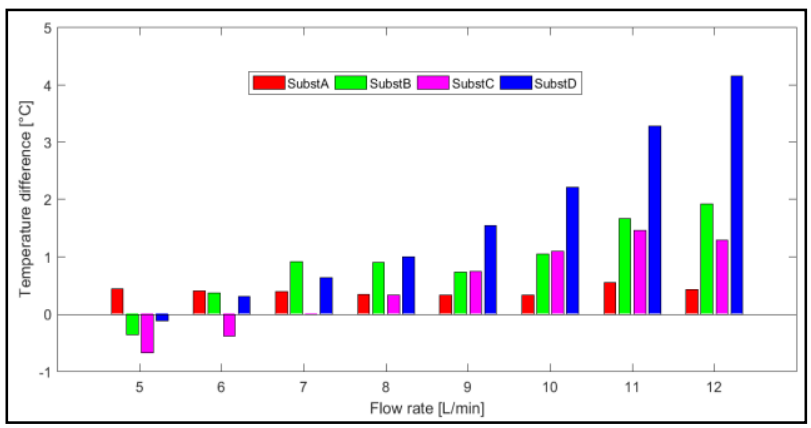

Fig.7. Deviation of the DHW temperature from the set-point of $45^{\circ} \mathrm{C}$ as a function of the DHW flow rate.

As shown, SubstA, having the electronic control, provides a stable DHW temperature all across the range of tested flows with a deviation of around $0.3{ }^{\circ} \mathrm{C}$. Substations B, C and D, having a SR valve for DHW, perform well at flows close to the flow rate at which they were set, $6 \mathrm{~L} / \mathrm{min}$ in this case. More specifically, for a DHW flow rate lower than the set flow rate, $5 \mathrm{~L} / \mathrm{min}$ in this case, the DHW supply temperature is higher than the set-point (temperature difference is negative). For flow rates higher than $6 \mathrm{~L} / \mathrm{min}$, the trend is a decrease in the DHW temperature, reaching a difference of 4 degrees for a flow rate of $12 \mathrm{~L} / \mathrm{min}$ for SubstD. Moreover, it is noticeable that the DHW temperature for substation A is much more stable that of the other substations: For a given flow rate, the DHW temperature does not vary more than $0.2{ }^{\circ} \mathrm{C}$ while for substations $\mathrm{B}, \mathrm{C}$ and $\mathrm{D}$ the variation is higher, reaching $2{ }^{\circ} \mathrm{C}$ in some cases. This temperature oscillation is not only due to the substation's control but also due to the supply temperature from the lab which was not always constant. However, those results show that the electronic control can cope better with a varying DH supply temperature compared to the SR control valves.

It can be deduced from the DHW tests that all the tested substations can provide the required set-point of 45 ${ }^{\circ} \mathrm{C}$ for a DH supply temperature of $55{ }^{\circ} \mathrm{C}$. However, depending on the type of dwelling they are installed in and on their commissioning, their performance and subsequently the occupants' thermal comfort might be affected. For substation A, it is enough to set the DHW temperature set-point in the software but for the SR valves, the installers must know the possible DHW demand to set the valves accordingly. It is advised to set the valve at the required temperature for the highest expected flow to avoid reductions in the thermal comfort. Also, the tests showed that the variations in the district supply temperature affects considerably the DHW temperature for the SR valve. For the electronically controlled valve, this effect is minimal.

\subsection{Stand-by/ keep warm tests}

The goal of the performed tests is to quantify the flow rate and the heat losses within the DHS that arise from the keep warm function.

During stand-by, there is no demand for SH or for DHW. This occurs often during the day when a dwelling's occupants are at work or during the night, when they are sleeping. Most of the substations in the market provide the keep-warm function that keeps the heat exchanger at a 


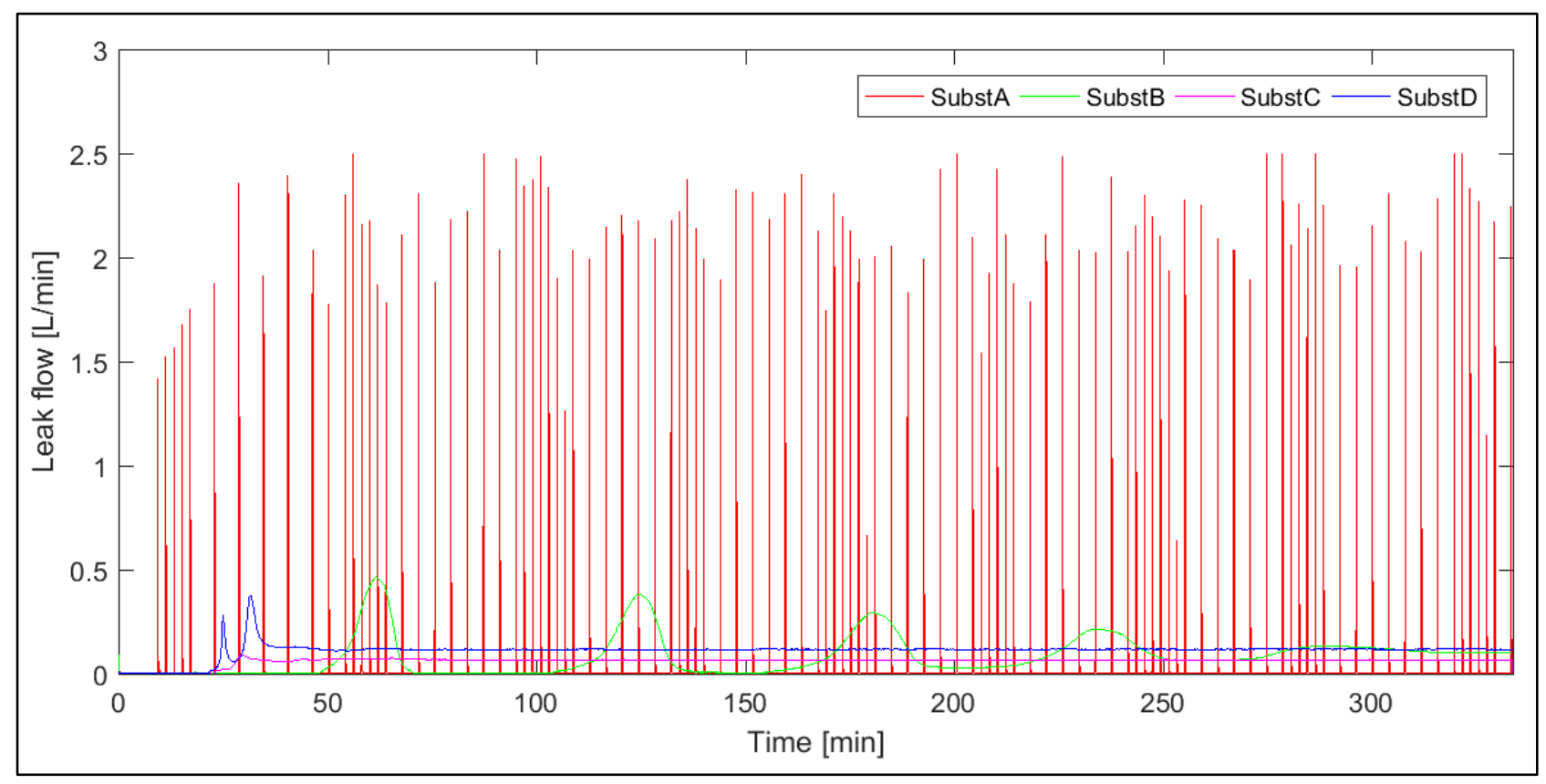

Fig.8. The primary flow of the 4 substations in function of time, for a period of 6 hours during a stand-by situation.

certain temperature to avoid delays in the delivery of DHW, which affects the comfort. For substations with electronic control, this function can be customized or even switched off, but it was kept at its default setting for the performed tests. For substations with a SR valve, this function is built into the valve and can't be modified.

The DHSs were tested for a period of around 6 hours, equivalent to a night-time during which no $\mathrm{SH}$ or DHW demand occurs. The DH supply temperature was again set to $55^{\circ} \mathrm{C}$, similar to the DHW preparation tests. Before the start of the measurements, the substations were in DHW operation mode for 10 minutes. To accurately measure the low flows that might be passing through the substation, the primary_low_flow meter was used instead of the primary_high_flow meter.

The results of the measurements for the 4 substations are shown in Fig.8. During the first 10 minutes, no primary flow is detected for all the substations. This is due to the heat exchangers being warm after the preparation of DHW before the start of the measurements. After this period, it can be noticed that the amount and duration of the primary flow varies among the DHSs. SubstA has a series of well controlled pulse flows varying between 1.5 and $2.5 \mathrm{~L} / \mathrm{min}$ whereas substations C and D's flows start by a small peak followed by a continuous flow of around 0.067 and $0.116 \mathrm{~L} / \mathrm{min}$ respectively. Substation B's behaviour is slightly different; the flow has a series of wide peaks at the beginning before becoming continuous by the end of the tests.

Further processing was performed on the gathered data and results are summarized in Table 2. The average DH supply temperature to the DHS, return temperature from the DHS and volume flow in the DHS were used to determine the average heat loss of the DHS during the 6 hours of testing. As shown, the average primary flow rate is considerable, having a minimum for SubstA of $2.77 \mathrm{~L} / \mathrm{h}$ and a maximum of $6.64 \mathrm{~L} / \mathrm{h}$ for SubstD. The heat dissipated is considered as a heat loss because the substation is not providing any DHW or SH. Those heat losses are the lowest for SubstA amounting to $47.83 \mathrm{~W}$ and highest for SubstD, reaching $92.58 \mathrm{~W}$. That is a continuous heat loss, for a period of 6 hours to keep the heat exchanger warm, in case there is a heat demand.

Those heat losses usually are unnoticed because the flow meters of the installed energy meters are not accurate enough to detect the low flows. For the district heating operators, those losses become noticeable with the increased number of substations in the network. This leads to higher overall losses in the $\mathrm{DH}$ system and to lower efficiencies. For this reason, the keep-warm function must be taken into account in the development of substations for low temperature $\mathrm{DH}$, especially the ones equipped with SR valves for the preparation of DHW.

Table 2. Stand-by/ Keep warm tests results.

\begin{tabular}{|c|c|c|c|c|}
\hline DHS & $\begin{array}{c}\text { Average } \\
\text { DH supply } \\
\text { temperature } \\
{\left[{ }^{\circ} \mathrm{C}\right]}\end{array}$ & $\begin{array}{c}\text { Average } \\
\text { DH return } \\
\text { temperature } \\
{\left[{ }^{\circ} \mathrm{C}\right]}\end{array}$ & $\begin{array}{c}\text { Average } \\
\text { flow } \\
\text { rate } \\
{[\mathrm{L} / \mathrm{h}]}\end{array}$ & $\begin{array}{c}\text { Average } \\
\text { heat } \\
\text { loss } \\
{[\mathrm{W}]}\end{array}$ \\
\hline SubstA & 48.19 & 31.92 & 2.77 & 47.83 \\
\hline SubstB & 46.82 & 30.18 & 4.99 & 88.96 \\
\hline SubstC & 46.07 & 32.51 & 3.71 & 52.37 \\
\hline SubstD & 48.97 & 35.78 & 6.64 & 92.58 \\
\hline
\end{tabular}




\section{Conclusions}

This paper discussed the development of a multipurpose test rig for testing heating equipment, specifically district heating substations. In this test rig, district heating supply conditions, space heating and DHW demand can be emulated.

Tests were performed on 4 different substations having different methods of supplying SH and DHW. The tests focused on the DHW operation and on the stand-by losses of those substations for low temperature district heating systems. For DHW preparation, electronic control provided the most stable supply temperature, independent of the DHW flowrate. For self-regulating valves, the results showed that it is important to set the valve correctly while commissioning because the substation performs well for DHW flowrates close to the set flow and it deviates from the set-point for the other flows. The results showed also that variations in the DH supply temperature have a considerable effect on the DHW temperature for the self-regulating valve whereas the effect is minimal for substations with electronic control.

Moreover, the tests demonstrated that DHSs are a source of heat losses within the DH network because of the built-in keep warm function. In general, this function can be customized for electronically controlled valves, but it is built-in for self-regulating valves. Again, the substation with the electronic control showed the lowest heat losses while the substations with the self-regulating valves contributed to higher losses. Given that the flow passing through he DHS's heat exchanger is small during stand-by, it is difficult for the commonly installed energy meters to detect those losses. However, on the DH scale, the losses lead to a lower overall efficiency. Therefore, with the decrease of the DH supply temperatures, DHS manufacturers have to pay extra attention to the keepwarm function, especially for the substations with selfregulating valves.

This work was performed with the support of the European Union, the European Regional Development Fund ERDF, Flanders Innovation \& Entrepreneurship and the Province of Limburg.

\section{References}

1. H.Gadd, S. Werner, Applied Energy, 157,51-59 (2015)

2. S. Frederiksen, S.Werner, District Heating and Cooling, (2013).

3. S.Mansson, P. Kallioniemi, M.Thern, T.Van Oevelen, K.Sernhed, Energy (to be published)

4. H.Gadd, S. Werner, Applied Energy, 136, 59-67 (2014)

5. Energimyndigheten, Publication ET,20, (2013) in Swedish.

6. S. Werner,Halmstad Höogskola. In Swedish (2013). 